\title{
A formação de professores de sociologia na região Norte: configurações e tendências
}

\section{The training of teachers of sociology at Northern Region: settings and trends}

Amurabi Oliveira - Universidade Federal de Santa Catarina. Licenciado e Mestre em Ciências Sociais (UFCG), Doutor em Sociologia (UFPE). Atualmente é professor da Universidade Federal de Santa Catarina (UFSC), atuando em seu Programa de PósGraduação em Sociologia Política. E-mail: amurabi1986@gmail.com

\section{Resumo}

A reintrodução da Sociologia no Ensino Médio em nível nacional a partir de 2008 provocou um impacto significativo na discussão sobre formação de professores nas Ciências Sociais Brasileiras, o que tem sido acompanhado da expansão significativa do número de cursos nos últimos anos, capitaneado principalmente pelo setor privado. Buscando compreender melhor essa realidade, analiso nesse trabalho a ampliação do número de licenciaturas em Ciências Sociais/Sociologia na Região Norte do Brasil, visando apreender as características dessa expansão e seus significados. Utilizo neste trabalho dos dados obtidos junto à plataforma http://emec.mec.gov.br/, que indicam um incremento no número de licenciaturas em Ciências Sociais/ Sociologia principalmente a partir de instituições privadas e de cursos na modalidade à distância.

\begin{abstract}
The reintroduction of Sociology in High School at the national level from 2008 caused a significant impact on the discussion of teacher training in Brazilian Social Sciences, which has been accompanied by a significant expansion in the number of undergraduate courses in recent years, led mainly by private sector. Seeking to better understand this reality, in this paper I analyze a larger number of degrees in Social Science / Sociology in Northern Brazil, aiming to understand the characteristics of this expansion and its meanings. Use of data obtained in this work with the http://emec.mec.gov.br/ platform, which indicate an increase in the number of degrees in Social Science / Sociology mostly from private institutions and undergraduate courses in distance mode.
\end{abstract}

\section{Palavras-chave}

Ensino de Sociologia; Formação de Professores; Ensino Superior.

\section{Keywords}

Sociology of Education; Teacher Training; Higher Education. 


\section{INTRODUÇÃO}

Em que pese a posição relativamente marginal que o debate educacional ocupa na Sociologia Brasileira, como pode ser atestado pelo parco número de linhas de pesquisa na pós-graduação que se voltam para essa discussão (LIMA, CORTES, 2013), cenário este praticamente inalterado nos últimos anos se compararmos com os balanços realizados anteriormente (WEBER, 1992), o que também pode ser verificado pela incipiência dos grupos de pesquisa dedicados à questão (OLIVEIRA, SILVA, 2014), a discussão sobre o Ensino Superior possui uma posição privilegiada no campo da Sociologia da Educação, especialmente naquela desenvolvida junto aos Departamentos de Ciências Sociais/Sociologia (NEVES, 2002b), todavia, há de se reconhecer que:

[...] apesar da centralidade do ensino superior no processo de desenvolvimento socioeconômico e na dinâmica da democratização da cultura e da cidadania nas sociedades modernas, seu tratamento sistemático tem merecido uma discreta atenção na agenda de pesquisa no interior das Ciências Sociais brasileiras contemporâneas quando comparado com outros temas. (MARTINS, WEBER, 2010, p. 157).

Acredito que há uma discreta mudança em curso, que tem aproximado a discussão das Ciências Sociais brasileiras do campo educacional como um todo, o que se deve, em grande medida, ao processo de reintrodução da Sociologia enquanto disciplina escolar na Educação Básica, desse modo a escola enquanto espaço de atuação dos egressos dos cursos de Ciências Sociais/Sociologia emerge como locus que precisa ser melhor conhecido no nível da pesquisa, assim como a prática docente e os espaços de formação inicial e continuada. Todavia, não podemos deixar de destacar que desde os anos de 1980 tem havido uma crescente proximidade da Sociologia Brasileira com o debate educacional (NEVES, 2002b), o que pode ser verificado pelo incremento da produção na área, bem como a partir da abertura de espaços institucionais para a divulgação de pesquisas nessa seara como o Grupo de Trabalho "Educação e Sociedade" junto aos encontros da Associação Brasileira de Pesquisa e Pós-Graduação em Ciências Sociais (ANPOCS) ${ }^{1}$.

O cenário em torno do Ensino de Sociologia no Brasil é substancialmente heterogêneo, tanto no que diz respeito à realidade existente nos diversos sistemas de ensino, uma vez que algumas unidades da federação introduziram a disciplina em seus currículos antes de 2008, além de haver uma variação considerável no quantitativo de aulas semanais, quanto na presença de agências formadoras de

A partir do $38^{\circ}$ encontro anual da ANPOCS o GT "Educação e Sociedade" deixou de existir dando lugar ao GT "Novas configurações do ensino superior na sociedade contemporânea", ao mesmo tempo em que se criou o Simpósio e Estudos Pós-Graduados intitulado "Ciências Sociais e Educação: dilemas e possibilidades na produção do conhecimento". 
professores de Sociologia, ainda que alguns dilemas persistam como a presença massiva de profissionais formados em outras áreas do conhecimento atuando como professores desta disciplina.

Compreendendo que há uma íntima relação entre a presença de determinada disciplina no currículo escolar e a dinâmica dos cursos superiores de formação inicial dos professores habilitados para lecioná-la, sendo assim, levantei como hipótese de trabalho inicial a ideia de que a reintrodução da Sociologia em nível nacional a partir da lei $n^{\circ}$ 11.648/08 teria implicado na expansão do número de licenciaturas de Ciências Sociais/Sociologia no Brasil como um todo, mas que possuiria particularidades em cada região.

Visando contribuir para o amadurecimento dessas questões proponho-me nesse texto realizar um exame mais de perto da realidade das licenciaturas em Ciências Sociais/Sociologia especificamente na região Norte do Brasil, buscando compreender quais suas características gerais e tendências que podem ser vislumbradas, especialmente a partir de 2008 quando a disciplina é reintroduzida no currículo escolar em nível nacional. O objetivo desse trabalho é analisar a expansão dos cursos de formação de professores de ciências sociais na região norte do país, analisando quais as características e tendências apresentadas nesse processo. Buscando realizar meu intento, dividirei esse trabalho em duas partes, na primeira realizarei uma discussão mais ampla sobre a formação de professores de Sociologia no Brasil, para assim melhor situar meu problema; e na segunda analisarei os dados disponíveis na plataforma http://emec.mec.gov.br ${ }^{2}$ / referentes às licenciaturas em Ciências Sociais/Sociologia existentes nesta região.

\section{A FORMAÇÃO DE PROFESSORES COMO UM DESAFIO PARA AS CIÊNCIAS SOCIAIS BRASILEIRAS}

Em um texto, que apesar de relativamente recente é bastante seminal para a discussão sobre o Ensino de Sociologia no Brasil, Moraes (2003), partindo da experiência da Universidade de São Paulo, aponta para o lugar periférico que a licenciatura ocupa nos cursos de Ciências Sociais, o que pode ser compreendido por um lado, pela distância que a discussão educacional assumiu com relação aos departamentos de Ciências Sociais/Sociologia principalmente a partir da Reforma Universitária de 1968 com o advento das Faculdades de Educação (SILVA, 2002); por outro, pela intermitência da disciplina nos currículos escolares (MORAES, 2011; OLIVEIRA, 2013b), que não se constituiu como um campo de atuação estável para os egressos dos cursos de Ciências Sociais, especialmente a partir da segunda metade do século XX.

2 A coleta dos dados na plataforma foi realizada entre os meses de agosto e setembro de 2014. 
Outro fator a ser considerado diz respeito ao fato de que, no momento em que a Sociologia se faz ausente no currículo escolar, ocorre um intenso processo de expansão e solidificação da pós-graduação no Brasil, de tal modo que o foco das Ciências Sociais passa a recair sobre o desenvolvimento de pesquisas especialmente nesse nível, tornando-se o debate sobre o Ensino algo secundário, ainda que se possa indicar vozes pontuais que se posicionam ante esta questão, como o próprio Florestan Fernandes (1920-1995) que realizou uma fala durante o primeiro Congresso Brasileiro de Sociologia, em 1954, intitulada “O Ensino da Sociologia na Escola Secundária Brasileira", mas que longe de se resumir a uma posição militante, no sentido vulgar do termo, buscava perceber as possibilidades existentes da Sociologia na escola contribuir para a consolidação de um projeto democrático de sociedade (FERNANDES, 1980), que pode ser encarada como finalidade última da educação no pensamento do sociólogo paulista.

Como a partir dos anos de 1980, a Sociologia começa a retornar paulatinamente aos currículos escolares. A discussão sobre a licenciatura aos poucos também passa a assumir outros contornos, o que também é influenciado pelas mudanças mais amplas que ocorrem nesse momento, como a publicação da nova Lei de Diretrizes e Bases da Educação (LDB) de 1996 (lei no 9.394). Segundo Weber (2007, p. 186):

A Lei n. 9.394/1996, ao reunir, de forma indissociável, escola e atividade docente na tarefa de assegurar a aprendizagem dos alunos, induz a delimitação de uma área de jurisdição, ao mesmo tempo em que estabelece os marcos orientadores dos projetos de formação de uma atividade que se tornou essencial à sociedade brasileira. Esse aspecto constitui para alguns autores, como Freidson, por exemplo, um indicador importante da passagem de uma ocupação para uma profissão. Tais marcos, consubstanciados em Diretrizes Curriculares Nacionais para a Formação de Professores da Educação Básica em nível superior, ainda não assimiladas pela comunidade acadêmica, e não mais em currículos mínimos, devem induzir à composição de projetos pedagógicos diferenciados, que expressem os vínculos do processo formativo com a perspectiva de futuro do país adotada por seus formuladores. Para a literatura especializada, esse constitui um outro indicador do processo de profissionalização de uma atividade no mundo do trabalho

Estas questões também impactam nos cursos de Ciências Sociais/ Sociologia, porém há ainda um fator particular que deixa marcas profundas nesses cursos: a sua intermitência histórica, que tem impossibilitado o desenvolvimento linear de um amadurecimento nas discussões sobre os diversos modelos formativos, o que tem sido trazido para o centro da questão a partir da reintrodução da disciplina no currículo escolar. Nesse ponto específico é válido destacar que a formação de professores de Ciências Sociais/Sociologia articulase a partir de dois eixos principais: 
[...] a) do cenário mais amplo das políticas de formação docente, operacionalizado no Brasil principalmente através da Lei de Diretrizes e Bases da Educação, mas também de outras regulamentações posteriores, bem como por meio das colocações de diversas entidades acadêmicas e profissionais; b) da compreensão do papel Sociologia na Educação Básica por parte dos gestores públicos,do próprio meio acadêmico e das instâncias profissionais. (OLIVEIRA, 2013a, p. 148).

Tratando-se, por excelência, de um cenário ainda em consolidação, e que, acompanhando uma tendência mais geral no campo da formação docente no Brasil, apresenta uma multiplicidade de modelos formativos, tendo como crivagem fundamental o binômio professor/pesquisador (HANDFAS, 2009).

Além da própria reintrodução da disciplina no currículo escolar, como já enfatizei, outros fatores devem ser considerados no processo de amadurecimento da questão como a ampliação do número de pesquisas sobre o Ensino de Sociologia, tendo como consequência o incremento da produção acadêmica nesse campo; a abertura de espaços institucionais para a circulação das discussões, como o Grupo de Trabalho de "Ensino de Sociologia" que vem ocorrendo junto ao Congresso da Sociedade Brasileira de Sociologia desde 2005; o Encontro Nacional sobre o Ensino de Sociologia na Educação Básica, que vem ocorrendo de forma bianual desde 2009; e a criação da Associação Brasileira de Ensino de Ciências Sociais em 2012.

Além do mais, as diversas políticas públicas ${ }^{3}$ que atuam tanto na Educação Básica quanto nos cursos de formação de professores devem ser compreendidas como relevantes nesse processo, cabendo aqui destacar ao menos duas delas: 1) a introdução da Sociologia no Plano Nacional do Livro Didático (PNLD) a partir de 2012, tendo sido aprovados dois livros no primeiro edital e seis no segundo (PNLD, 2015); 2) o advento do Programa Institucional de Bolsas de Iniciação à Docência (PIBID), que tem sido compreendido como uma medida relevante para as licenciaturas de modo geral, mas que assume uma posição ainda mais significativa nas Ciências Sociais que devido à intermitência de sua presença na Educação Básica não possui uma continuidade nas discussões pertinentes ao Ensino.

Estas são algumas questões basilares sucintamente aqui expostas que se fazem necessárias para a compreensão do debate sobre a formação de professores de Ciências Sociais/Sociologia no Brasil, ainda que elas representem apenas um lastro geral mais amplo não levando em consideração as particularidades de cada região,

Ao me referir às políticas públicas educacionais compreendo que: “a) que as políticas públicas são emanadas do poder público, logo, nos remetem a uma dimensão com o Estado, afetando tanto as instituições públicas quanto privadas; b) que têm como objeto de reflexão específica a própria realidade educacional, em especial a escolar.” (OLIVEIRA, 2013a, p. 133-134). 
que dizem respeito à realidade da graduação e da pós-graduação, à menor ou maior participação do setor público nesses cursos de formação, bem como a maior ou menor proximidade entre as Universidades e as Secretarias Estaduais de Educação.

Passemos então para a análise dos dados referentes à criação de novas licenciaturas em Ciências Sociais/Sociologia na região norte do país a partir de 2008, o que será examinado considerando tanto as questões particulares referentes ao Ensino de Sociologia, quanto a discussão mais geral sobre a expansão do Ensino Superior no Brasil.

\section{O CENÁRIO DAS LICENCIATURAS EM CIÊNCIAS SOCIAIS/ SOCIOLOGIA NA REGIÃO NORTE}

Nos estudos que vêm sendo desenvolvidos no Brasil nas últimas décadas, tem ficado evidente a expansão paulatina do Ensino Superior, o que se deu com grandes saltos ao menos em dois períodos de forma mais visível: nos anos de 1970 e a partir da segunda metade da década de 1990. Nesse sentido, é importante ressaltar que este processo foi capitaneado principalmente pelo setor privado, sendo esta sua principal característica (NEVES, 2002b), e a partir dos anos de 1990, principalmente, encontramos um protagonismo estabelecido pelas instituições não universitárias. Para uma melhor compreensão desse processo, é relevante considerar o papel decisivo que teve a Reforma Universitária de 1968 para tanto. Segundo Martins (2009, p. 28):

O "novo" ensino superior privado de perfil empresarial surgiu na medida em que as universidades públicas, sobretudo as federais, modernizadas pela Reforma Universitária de 1968, não conseguiram atender à crescente demanda de acesso. Sua expansão foi possível devido à retração do ensino público na absorção da demanda. As complexas alianças políticas que os proprietários das empresas educacionais estabeleceram com determinados atores dos poderes executivo e legislativo, nas últimas quatro décadas, possibilitaram essa multiplicação. Por sua vez, o espesso cipoal de leis, decretos, resoluções de conselhos e portarias ministeriais que se instalou no país lhes permitiu descumprir determinações legais que regulamentam o funcionamento das instituições e/ou reverter decisões desfavoráveis aos seus interesses junto ao poder judiciário.

Ainda segundo a análise do autor, a simples ampliação do número de vagas no setor privado não garantiu a democratização do Ensino Superior, tendo transformado "[...] um direito da cidadania moderna num privilégio individual, convertendo sua clientela em consumidores de produtos educacionais, impondo pesados custos financeiros e humanos a uma parte expressiva dos seus estudantes. " (Ibidem, p. 29). 
Este cenário se deu de forma relativamente hegemônica no país, porém chamo a atenção para o fato de que no caso específico das licenciaturas em Ciências Sociais, dado a inexistência de um campo de atual estável para os egressos desse curso, o cenário apresentou certas particularidades. Em algumas regiões, como no Nordeste, os cursos continuaram concentrados em instituições públicas de ensino, havendo inclusive o fechamento no período recente de alguns dos poucos existentes na iniciativa privada (OLIVEIRA, 2014), o que pode ser entendido como um padrão recorrente nas regiões mais periféricas em termos acadêmicos.

É importante destacar que, quando nos referimos ao Ensino Superior, Privado no Brasil, acabamos por nos voltar a uma realidade profundamente heterogênea, na qual existem tanto universidades que se dedicam incisivamente às atividades não só de ensino como também de pesquisa e de extensão, quanto outras instituições não universitárias ${ }^{4}$, que, a partir de um viés mais mercadológico, passam a ofertar cursos de curta duração cuja qualidade tem sido por vezes questionada ante os sistemas de avaliação do Ensino Superior. Também há certa heterogeneidade no próprio setor público, ainda que nesse caso haja um predomínio do modelo universitário de ensino, porém também há aí instituições substancialmente diversas, cujas condições objetivas para o desenvolvimento das atividades de ensino, pesquisa e extensão são bastante diversas. Na própria rede federal de ensino, podemos encontrar tanto as universidades federais, quanto os institutos federais, que possuem modelos institucionais bastante diversos.

Compreendo que há uma íntima relação entre a existência de cursos de Ciências Sociais/Sociologia, especialmente no que diz respeito às licenciaturas, e a presença da Sociologia como componente curricular escolar, de tal modo que devemos interpretar como polos visceralmente ligados a Educação Básica e o Ensino Superior, as transformações que ocorrem naquela têm um impacto direto sobre as possibilidades de expansão das licenciaturas neste. Nesta direção, chamo a atenção para o fato de que o Pará foi um dos primeiros estados brasileiros a reintroduzir a Sociologia nos currículos escolares antes de sua obrigatoriedade ainda no ano de 1985, além de estar presente na rede estadual de ensino também no Ensino Fundamental.

4 De acordo com a Resolução $\mathrm{CNE} \mathrm{n}^{\circ}$ 3/2010, é necessário para que uma instituição seja credenciada como universidade: a) possuir um terço do corpo docente com a titulação de mestre ou doutor, b) um terço do corpo docente com regime de trabalho em tempo integral, c) Conceito Institucional (IC) e Índice Geral de Curso (IGC) igual ou superior a 4, d) oferta regular de, no mínimo, $60 \%$ (sessenta por cento) dos cursos de graduação reconhecidos ou em processo de reconhecimento devidamente protocolado, no prazo regular, e) ofertar de forma regular pelo menos quatro cursos de mestrado e dois de doutorado, f) compatibilidade do Plano de Desenvolvimento Institucional (PDI) e do Estatuto com a categoria de universidade, g) não ter sofrido, nos últimos 5 (cinco) anos, relativamente à própria instituição ou a qualquer de seus cursos, as penalidades de que trata o $\int 1^{\circ}$ do art. 46 da Lei $n^{\circ} 9.394 / 1996$, regulamentado pelo art. 52 do Decreto n ${ }^{\circ} 5.773 / 2006$. 
Outra chave importante para compreendermos as dinâmicas que passam a ser assumidas na interrelação entre Educação Básica e Ensino Superior diz respeito à presença ou ausência de uma determinada disciplina nas formas de ingresso no Ensino Superior, especialmente nas Universidades Públicas. Neste caso, me volto novamente à experiência paraense tendo em vista que a Sociologia passou a contar no vestibular dessa universidade desde 2005. Segundo Palhano (2007, p. 7):

Considerando o cenário de crises sócio políticas e educacionais ocorridas na sociedade brasileira é que Universidade Federal do Pará, (UFPA) no ano de 2005, articulada com os setores da sociedade civil paraense (escolas públicas, sindicatos dos trabalhadores do ensino público, dos sociólogos, Secretária de Educação estadual e Municipal, parlamentares e outros), Implanta no Processo Seletivo Seriado (PSS)- Antigo Vestibular- Sociologia na $1^{a}$ fase do PSS, para compor o conjunto de disciplinas a serem avaliadas. Para a elaboração do programa, procuramos levar em consideração os seguintes documentos: Programa de Ensino de Sociologia ao nível Médio da Secretaria Executiva de Educação/Pará, formalizada pelos professores do ensino médio. Conteúdos trabalhados nos cursos do nível médio de escolas e colégio da rede privada do Estado do Pará; material coletado durante as reuniões com os professores do ensino médio do Estado do Pará. Examinamos ainda, as propostas de conteúdos de sociologia para o ensino médio dos Estados de São Paulo, Minas gerais, Rio de Janeiro, e os Parâmetros Curriculares Nacionais- MEC- ensino médio, entre outros.

Acredito que este é um aspecto relevante a ser destacado na medida em que há uma forte correlação entre a posição que determinada disciplina ocupa na hierarquia do currículo escolar e seu lugar nas formas de ingresso ao Ensino Superior, especialmente ante ao processo de expansão desse, de tal modo que este também deve ser um fator considerado na análise do aumento do número de licenciaturas em Ciências Sociais/Sociologia. Ainda que este tema também nunca tenha ocupado um lugar de destaque junto às associações científicas (HANDFAS, 2012), as mudanças institucionais que vem sendo vivenciadas tem colocado a questão da formação de professores como um desafio para as Ciências Sociais no Brasil, seja no que diz respeito à necessidade de se pensar os modelos formativos existentes, seja na busca por novas possibilidades de formação docente que possam atender às demandas que se colocam nesse momento.

Para um melhor exame das questões que expus aqui até o momento, apresentarei quais as instituições que ofertavam licenciaturas em Ciências Sociais/ Sociologia na região norte até antes do ano de 2008; indicando ainda se são públicas ou privadas; se são cursos presenciais ou na modalidade de Educação e a Distância (EAD); e qual a denominação que se utilizam (se Ciências Sociais ou Sociologia); e ano de criação. 


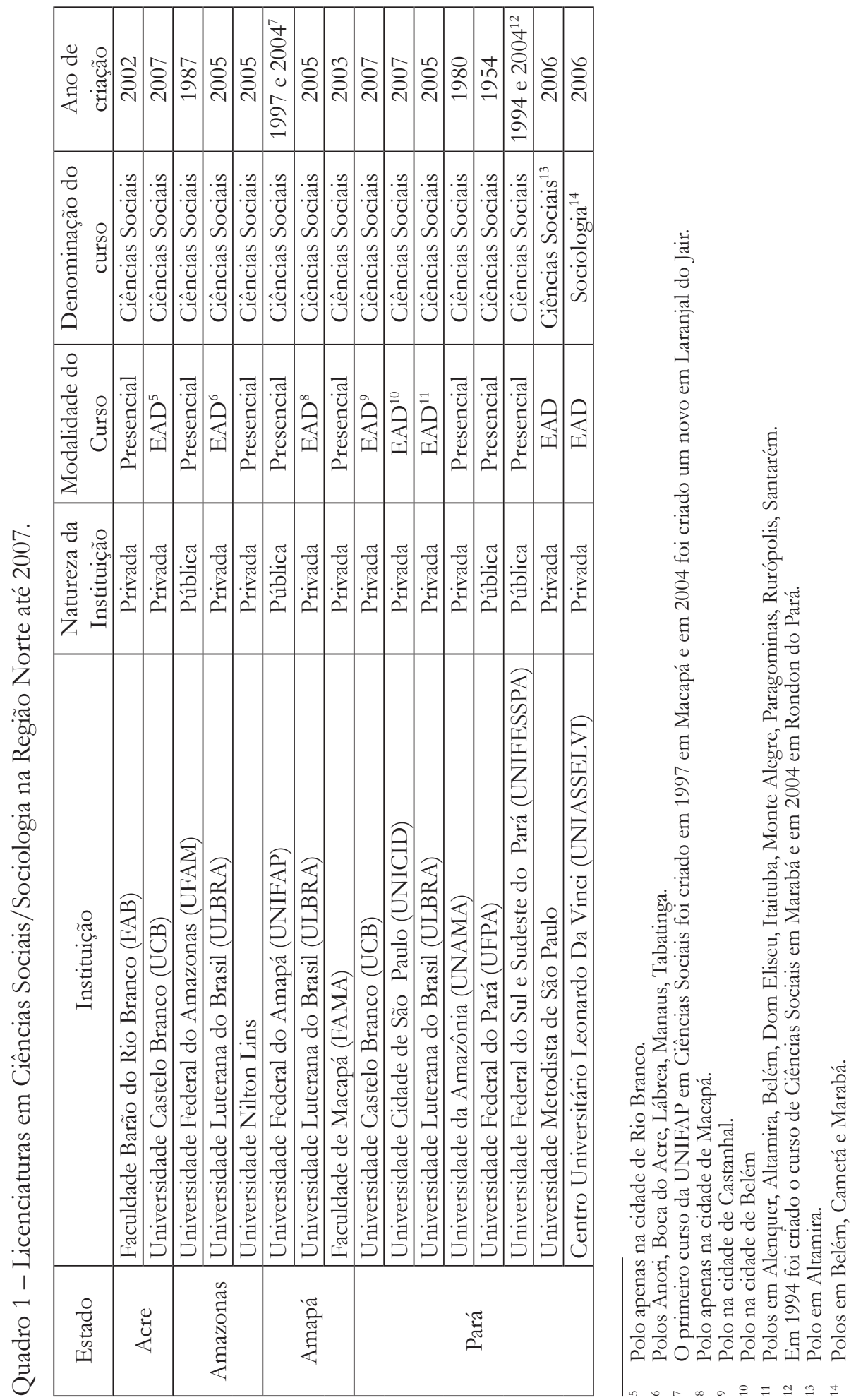



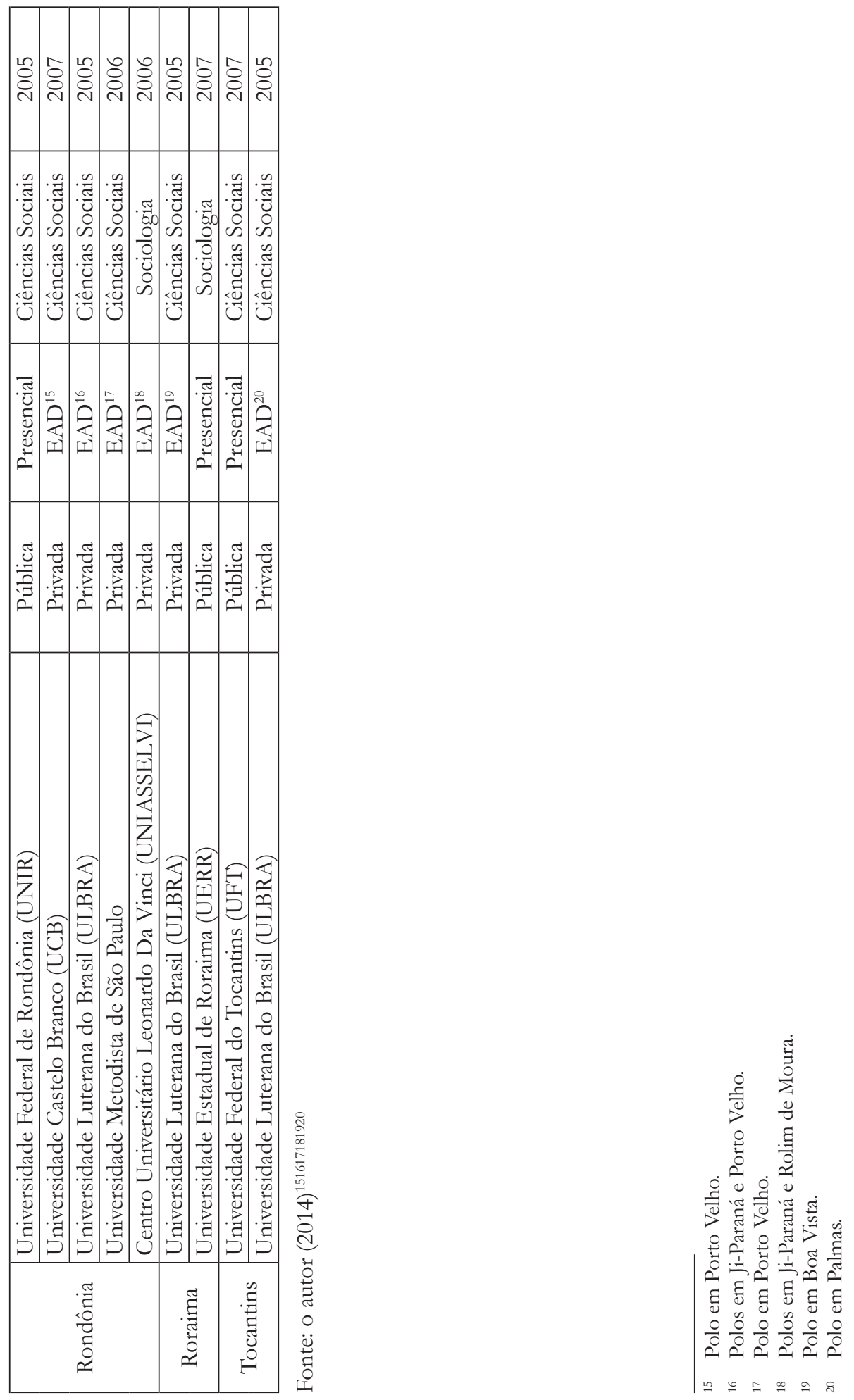
Antes de adentrar na análise dos dados, creio que é relevante apontar alguns limites da fonte de dados, pois encontrei algumas dissonâncias entre os dados apresentados na plataforma emec.mec.gov.br e aqueles que constavam nos sites das Instituições de Ensino Superior (IES). Por exemplo, segundo a plataforma, a Universidade Federal do Oeste do Pará (UFOPA) ${ }^{21}$ possui uma licenciatura em Ciências Sociais desde 1991 na cidade de Santarém; assim como de Ouro Preto do Oeste (UNEURO) em Outro Preto do Oeste (RO), todavia, estas informações inexistem nos sites das respectivas instituições, não havendo a oferta de tal curso nos seus últimos editais de vestibulares. Portanto, para uma confiabilidade dos dados, foram verificadas as informações sobre a existência ou não do curso junto ao site de todas as instituições citadas na plataforma. Também chamo a atenção para o fato de que não explorarei nesse artigo o crescimento do número de vagas ofertadas, pois focarei aqui, exclusivamente, no processo de criação de novos cursos de formação de professores de Sociologia, sem considerar o quantitativo de vagas disponíveis.

Um primeiro dado que me chamou atenção foi que em dois Estados (AC e RR), as principais IES públicas não possuem licenciatura em Ciências Sociais/ Sociologia, mas apenas o curso de bacharelado. No caso da UFRR, há ainda o curso de Licenciatura Intercultural Indígena, com ênfase em Ciências Sociais, mas que possui outro foco que não necessariamente a formação de professores de Sociologia, sendo que o termo Ciências Sociais assume nesse contexto sinônimo de Ciências Humanas. Em alguma medida, esse fato pode apontar tanto para a incipiência da discussão sobre a formação de professores de Sociologia quanto para o lugar periférico que a questão do Ensino ocupa junto às Ciências Sociais. No caso do Acre, inexiste, até então, licenciatura pública em Ciências Sociais/ Sociologia, e os dois cursos existentes até antes de 2008 apenas a ofertavam na capital, esta ausência de uma interiorização mais efetiva do curso também se faz presente em Roraima.

A primeira análise que podemos fazer de forma mais geral com relação ao conjunto de cursos é que sua criação é um fenômeno recente, tendo em vista que dos 25 cursos existentes até $2007^{22}$ apenas cinco haviam sido criados antes dos anos 2000, ou seja, 80\% deles foram criados entre 2000 e 2007, ou ainda,

21 Tanto ela quanto a UNIFESSPA surgem do desmembramento da UFPA.

22 Estou contabilizando a criação dos cursos nos diversos estados por instituições diferentes, de tal modo que não estou aqui contando em duplicidade quando a instituição possui mais de um curso presencial, ou ainda quando no caso das licenciaturas ofertadas na modalidade EAD possuem mais de um polo, este fenômeno especificamente será analisado mais adiante neste trabalho. 
de forma mais específica, entre os anos de 2005 e 2007 quando 18 deles são criados. Destes cinco cursos, três foram criados no Pará (UFPA 1954, UNAMA 1980, UNIFESSPA 1994), o que reflete o fato deste ter sido um dos primeiros estados no país a reintroduzir a Sociologia nos currículos escolares. Os outros cinco cursos criados nesta Unidade da Federação surgem após 2005, quando a Sociologia passa a constar no vestibular da UFPA. Percebamos, portanto, a intima relação entre os movimentos que ocorrem na Educação Básica e a dinâmica que as licenciaturas realizam no Ensino Superior. Interessante notar que os anos 2000 corresponde também ao período no qual se intensificam tanto a mobilização em torno do retorno da Sociologia ao currículo escolar, quanto a produção acadêmica sobre a temática, como aponta o balanço realizado por Handfas e Maçaira (2014).

Se entre os cursos existentes até os anos 2000 havia um predomínio das instituições públicas de Ensino, tendo em vista que dos cinco cursos quatro (80\%) estavam alocados em instituições públicas de ensino, mais especificamente em instituições federais, todavia, o processo de expansão do número de licenciaturas em Ciências Sociais/Sociologia seguiu a tendência mais ampla a expansão conservadora do Ensino Superior Brasileiro, tendo em vista que, dos 20 cursos criados após os anos 2000, 17 (85\%) são privados, totalizando 18 dos 25 existentes até 2007 na região norte. Também chama a atenção que há um progressivo aumento dos cursos na modalidade EAD. Se até o final dos anos de 1990, eram inexistentes, a partir dos 2000 passam a representar parcela significativa destes cursos. Dos 20 criados entre 2000 e 2007, 14 (70\%) são nessa modalidade, ou 56\% do total de cursos existentes até então, de tal modo que os cursos presenciais passam a ficar cada vez mais restritos às instituições públicas de ensino, uma vez que dos 11 ofertados presencialmente, 7 (63\%) são públicos.

Portanto, ainda que tenham passado a ocupar progressivamente um lugar menor na oferta total de licenciaturas em Ciências Sociais/Sociologia, os cursos públicos ainda ocupam um protagonismo na oferta presencial. Não sem menor relevância vale ressaltar que a maioria dos cursos presenciais se concentram nas capitais dos estados, ao passo que aqueles ofertados na modalidade EAD por meio de seus polos apresentam um intenso grau de interiorização.

Por fim, ainda que timidamente, passam a surgir nesse período cursos cuja denominação é Sociologia e não mais Ciências Sociais, esta refere-se à tradição intelectual instaurada desde criação dos primeiros cursos nos anos de $1930^{23}$,

23 Os primeiros cursos de Ciências Sociais criados no Brasil foram na Escola Livre de Sociologia 
ao passo que aquela demarca uma aproximação clara com a disciplina escolar, indicando que a criação destes vinculam-se diretamente à demanda que emerge na Educação Básica, ainda que suas grades curriculares permaneçam assentadas no tripé da Antropologia, Ciência Política e Sociologia.

Considerando tais questões, passemos à análise do cenário inaugurado com a reintrodução da Sociologia em nível nacional a partir de 2008. Frisase que, mesmo nos Estados em que esta disciplina havia sido reintroduzida anteriormente, é com a lei 11.648/08 que ela ganha maior legitimidade junto às burocracias das Secretarias Estaduais de Educação, institucionalizando-se de fato, ainda que tenhamos cenários substancialmente heterogêneos no país afora. Em todo o caso, já em 2006, temos o Parecer CNE/CEB no 36/08 que introduz a Sociologia nos currículos escolares, o que nos ajuda a compreender a criação de dois cursos públicos no ano seguinte (UFT e UERR). Em ambos os casos, tratase dos únicos cursos públicos de seus estados.

Observamos então o surgimento de 18 novas Licenciaturas em Ciências Sociais/Sociologia na região Norte a partir de 2008, demarcando um crescimento de $72 \%$ com relação ao número existente anteriormente. Ainda que possamos compreender que houve também um crescimento substancial entre os anos de 2005 e 2007, quando os estados passam a introduzir a disciplina paulatinamente em seus currículos, há de se reconhecer as particularidades do crescimento apresentado nesse período mais recente. O primeiro delas é o fato de que apenas surgiram cursos privados e na modalidade $\mathrm{EAD}$, de tal forma que passa a se consolidar definitivamente a oferta da licenciatura em Ciências Sociais/Sociologia nesse formato, já que das 43 licenciaturas existentes até o momento $32(74 \%)$ são nesse formato.

Ainda mais singular é o fato de que essa expansão ocorrida a partir de 2008 é conduzida por apenas três conglomerados educacionais, ainda que algo semelhante tenha ocorrido no período anterior quando a ULBRA passou, em 2005, a ofertar a licenciatura em Ciências Sociais em vários polos em todos os estados da região Norte, exceto no Acre; o UNIASSELVI, a licenciatura em Sociologia em Rondônia e no Pará a partir de 2006; e a Universidade Metodista de São Paulo a licenciatura em Ciências Sociais em Rondônia e no Pará, também a partir de 2006, porém no período anteriormente analisado houve o surgimento também de cursos presenciais, públicos e uma maior pluralidade de instituições envolvidas.

e Política de São Paulo (1933), na Universidade de São Paulo (1934) e na Universidade do Distrito Federal (1935) no Rio de Janeiro, ainda que este último tenha tido uma breve existência encerrando suas atividades em 1939. 


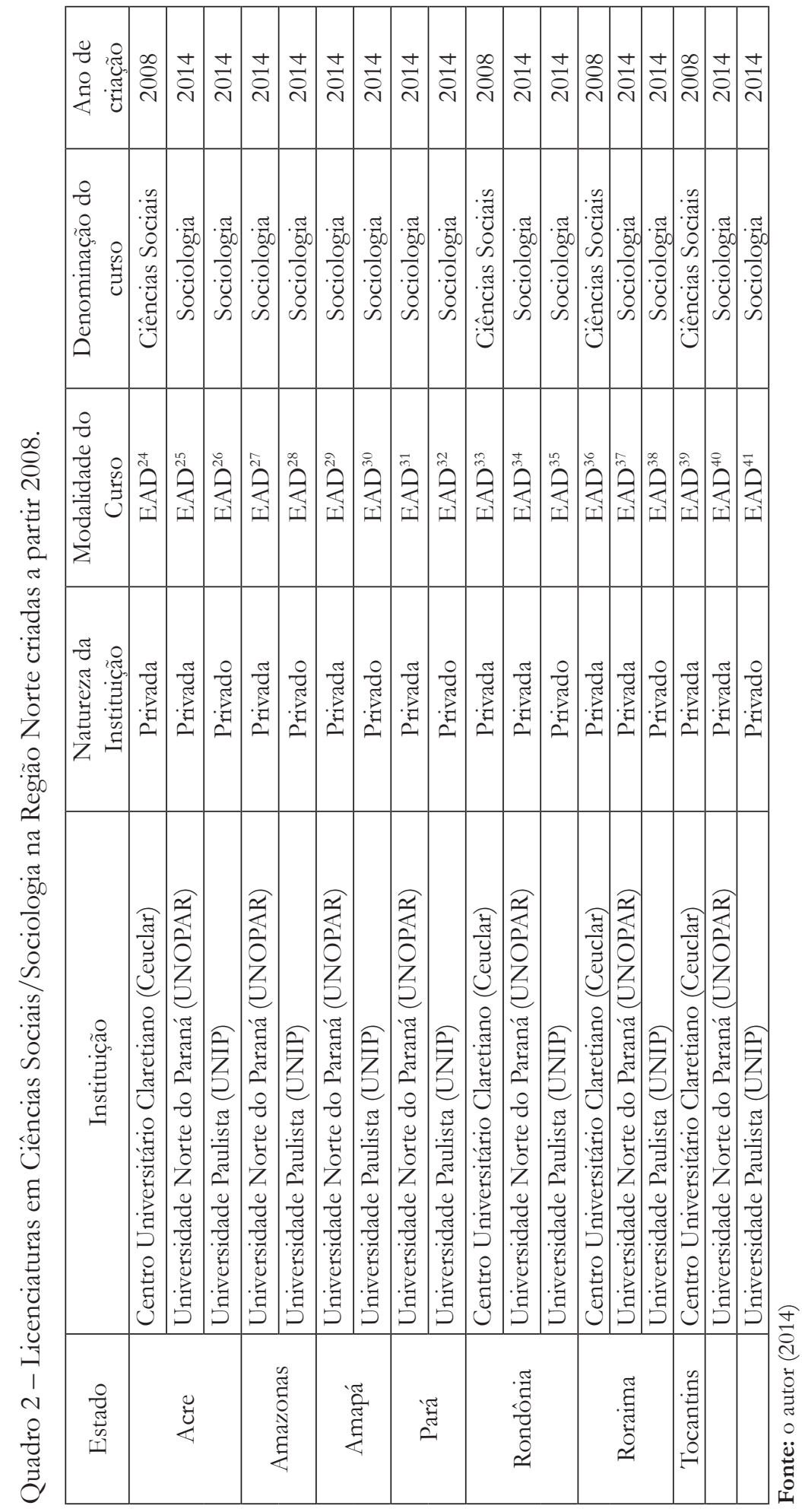




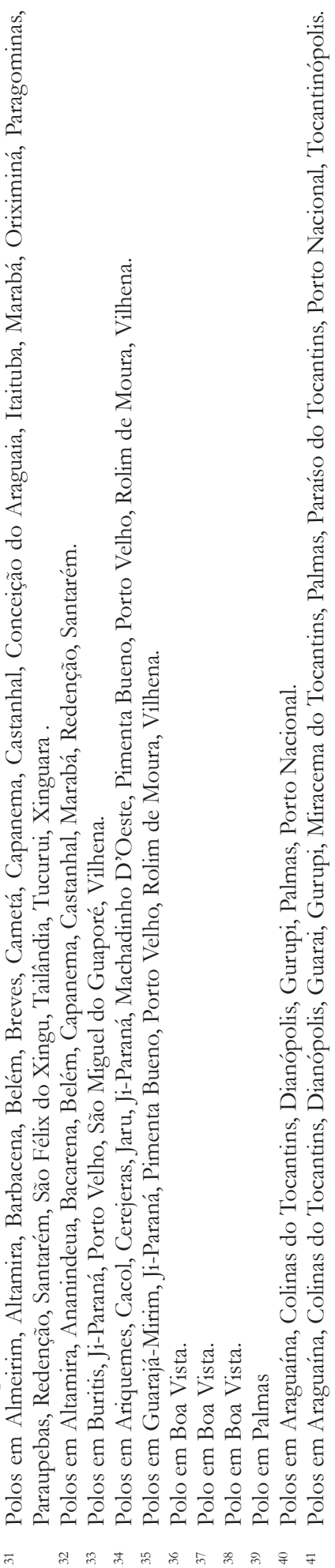

Novos Cadernos NAEA • v. 19 n. 1 • p. 253-274 • jan-abril. 2016 
A partir de 2008 o Ceuclar passou a ofertar a licenciatura em Ciências Sociais no Acre, Rondônia, Roraima e Tocantins, ao passo que a UNOPAR e a UNIP passaram a atuar em todos os estados da região Norte ofertando a Licenciatura em Sociologia a partir de 2014, de tal modo que também chama a atenção o fato de a maior parte absoluta (83\%) dessas novas licenciaturas possuem a mesma denominação que a disciplina escolar, o que reforça a finalidade do curso enquanto uma resposta a demanda emergente pela formação de professores na Educação Básica.

$\mathrm{Na}$ literatura existente sobre Ensino de Sociologia, mais especificamente no que diz respeito às análises acerca dos cursos de formação de professores, ainda é incipiente a discussão envolvendo essa formação nas IES privadas, e mais ainda nos cursos na modalidade EAD, o que em parte pode ser explicado pelo fato de que a maior parte das pesquisas em nível de pós-graduação stricto sensu são realizadas em universidades públicas, que tendem a assumir como objeto preferencial de investigação os espaços formativos junto às próprias IES públicas, nas quais a experiência com a formação de professores de Ciências Sociais/Sociologia ainda é bastante insignificante numericamente ${ }^{42}$.

Reconheço aqui a necessidade de aprofundarmos nossa análise sobre as licenciaturas em Ciências Sociais/Sociologia nas IES privadas e na modalidade EAD, considerando a centralidade que estes cursos passam a assumir na formação de professores de Sociologia para a Educação Básica, ainda que não reconheça aí um processo de democratização do acesso ao Ensino Superior, pelo contrário, os entraves para tanto são evidentes, como podemos perceber pela inexistência no estado do Acre de qualquer licenciatura pública em Ciências Sociais/Sociologia. Há de se ter no horizonte, em todo o caso, que iniciativas como o Plano Nacional de Formação de Professores da Educação Básica (PARFOR) contribuem com o processo de constituição de uma democratização da formação docente em Ciências Sociais/Sociologia, porém como este plano possui um caráter assumidamente emergencial, além de outras características bastante idiossincráticas, não será objeto de análise nesse trabalho.

No caso da EAD há de se pensar ainda seus limites no que diz respeito às demandas próprias da formação em Ciências Socais/Sociologia que são estabelecidas pelas diretrizes nacionais do curso, uma vez que há uma necessidade real que os alunos egressos tenham conhecimento dos referenciais clássicos e

42 Segundo o site da Universidade Aberta do Brasil (UAB) há atualmente licenciaturas em Ciências Sociais na modalidade EAD nas seguintes instituições públicas: Universidade Federal de Alagoas (UFAL), Universidade Federal de Viçosa (UFV), Universidade Estadual de Montes Claros (UNIMONTES), e com a denominação de Sociologia na Universidade Federal de Santa Maria (UFSM), e na Universidade Federal do Amapá (UNIFAP). 
contemporâneos das Ciências Sociais em termos teóricos e metodológicos (BRASIL, 2001). Além do mais:

[...] em que pese os esforços das instituições públicas em tentar manter o mesmo padrão de qualidade em termos de formação dos cursos presenciais, deve-se reconhecer os limites postos, que se referem principalmente, mas não exclusivamente, ao descompasso existente entre a forma de produção de materiais didáticos e as necessidades postas na produção do conhecimento das Ciências Sociais. (OLIVEIRA, BRUM, 2014, p. 17).

Portanto, precisamos examinar melhor os projetos pedagógicos dos cursos, seus desenhos curriculares, a formação do quadro docente, os tutores, o material utilizado, as formas de interação por meio das plataformas virtuais, bem como o perfil dos alunos que buscam tais cursos.

Todavia, ainda que ocupem nesse momento apenas uma pequena proporção do total de cursos de formação de professores de Sociologia na região norte, as IES públicas continuam sendo centrais por várias razões. A primeira e mais evidente delas é sua centralidade no processo de produção de conhecimento no próprio campo das Ciências Sociais, ainda que não exclusivamente, mas principalmente por meio da pós-graduação.

Apenas em duas IES na região Norte, encontramos cursos de pósgraduação stricto sensu em Ciências Sociais, na UFPA, que possui o programa de pós graduação em Ciências Sociais criado em 2002, e o em Antropologia criado em 2010 que ofertam cursos de mestrado e doutorado; na UFAM, o programa de pós graduação em Sociologia criado em 2007 em nível de mestrado, e o em Antropologia criado em 2008, ofertando inicialmente cursos em nível de mestrado e, a partir de 2010, também de doutorado. Sendo assim, acredito que não podemos desconsiderar o papel que estas instituições possuem também na formação de quadros para as demais instituições que atuam na região, e mesmo na formação continuada dos egressos dos demais cursos.

Não podemos olvidar ainda que o crescimento das instituições privadas se deu de forma concomitante a uma crescente hierarquização do campo acadêmico.

Dessa forma, algumas universidades públicas (federais e estaduais) e determinadas universidades privadas (geralmente as confessionais) se organizaram gradualmente, de modo a se aproximarem de um modelo acadêmico neo-humboldtiano. Essas instituições criaram estruturas acadêmicas que propiciaram a produção científica institucionalizada, desenvolveram cursos de pós-graduação stricto sensu, promoveram a profissionalização da carreira acadêmica, adotaram o regime de tempo integral para seus docentes, preservaram a liberdade acadêmica, associaram as atividades de ensino e pesquisa, implantaram programas de 
iniciação cientifica em parceria com agências de fomento nacionais. Em 2006, as universidades públicas federais e estaduais concentravam $70 \%$ dos docentes de tempo integral e 64\% dos doutores no país (Scott, 2006; Sguissardi, 2005; Casper \& Humbolt, 1997; Charle \& Verger, 1994).

Por sua vez, as instituições privadas de perfil empresarial estruturaram atividades que guardam certas afinidades acadêmicas com o modelo neo-napoleônico. De modo geral, essas instituições basicamente estão voltadas para uma estrita formação profissional e empregam professores horistas com pequeno volume de titulação acadêmica, que se dedicam em sua maior parte às atividades de ensino. Predomina em seu interior uma ausência de estruturas consolidadas de pesquisa e de pós-graduação stricto sensu. As instituições particulares com fins lucrativos concentram apenas $14 \%$ dos docentes de tempo integral e 16\% dos doutores do país.

Existem diferenças qualitativas entre as instituições públicas e privadas, mas é também possível constatar assimetrias no interior de cada um desses segmentos.

A forma pela qual se deu a expansão do ensino superior no período em foco torna evidente que a simples ampliação de vagas no setor privado não ofereceu nenhuma garantia para sua democratização. $\mathrm{O}$ acesso ao ensino superior brasileiro continua restrito a aproximadamente $12 \%$ dos estudantes na faixa etária de 18-24 anos, o que contrasta com países mais avançados que têm absorvido aproximadamente $60 \%$ de jovens dessa faixa de idade (Barreyro, 2008; McCowan, 2007; Neves, 2005). (MARTINS, 2010, p. 28-29).

Penso que estes fatores devem ser considerados para melhor compreendermos a dinâmica que está se formando nos cursos de Ciências Sociais/Sociologia não apenas na região Norte do país mas no Brasil como um todo, tendo em vista que o processo de reintrodução da Sociologia no nível médio tem dinamizado estes cursos e se colocam cada vez mais como um desafio para as Ciências Sociais brasileiras, um desafio histórico.

\section{CONSIDERAÇÕES FINAIS}

Por um lado, podemos observar que o processo de expansão do número de licenciaturas em Ciências Sociais/Sociologia na região norte seguiu uma tendência mais geral existente no Ensino Superior brasileiro, que diz respeito ao protagonismo assumido pelo setor privado principalmente. Todavia, devemos reconhecer as particularidades existentes, uma vez que essa expansão não acompanhou aquela que ocorreu a partir dos anos de 1970 no Brasil de modo geral, e mais ainda aquele que se deu entre os anos de 1995 e 2000, quando o setor privado cresceu 70,6\% (NEVES, 2002a). Ao que parece a participação do setor privado na oferta de cursos de formação de professores nessa área se deu 
a partir do momento em que passou a ficar mais claro o campo de atuação dos licenciados em Ciências Sociais/Sociologia, o que se deu ante ao processo de institucionalização da Sociologia no currículo escolar.

Com isso podemos perceber que se confirmaram nos dados obtidos as hipóteses aventadas nesse artigo acerca das tendências que estariam em curso nas licenciaturas em Ciências Sociais/Sociologia, uma vez que a tendência foi de uma expansão tardia dos cursos capitaneada pelo setor privado. Tal expansão é compreendida como tardia se pensarmos de forma comparativa com relação ao cenário mais amplo do Ensino Superior brasileiro, no qual a aceleração de sua expansão despontou já há algumas décadas.

O crescimento no número de licenciaturas em Ciências Sociais/Sociologia vincula-se diretamente à presença ou ausência da Sociologia nos currículos escolares (OLIVEIRA, 2015), não à toa, encontramos no Pará o maior número de cursos bem como os mais antigos, considerando a introdução da disciplina nesse estado ainda em 1985. A partir de 2005, passa a haver um incremento no número de cursos, o que aponta para o fato das Ciências Sociais serem algo recente na região, seja em nível de graduação ou de pós-graduação, a partir de 2008, quando a Sociologia passa a ser uma disciplina obrigatória em todas as séries do Ensino Médio me nível nacional, consolida-se um modelo de oferta de cursos de formação de professores assentados em instituições com um caráter mais empresarial, passando a ser amplamente majoritária a formação na modalidade EAD.

Há de se reconhecer que por meio das IES privadas, especialmente através dos cursos à distância, as licenciaturas em Ciências Sociais/Sociologia conseguiram se interiorizar, chegando a um número grande de municípios, o que é algo especialmente relevante na região Norte, considerando-se as grandes distâncias geográficas entre os municípios, sem embargo, reforço aqui que não enxergo nesse movimento um processo de democratização do Ensino Superior, uma vez que se coloca em termos de mercado o que deveria ser entendido como direito.

Ainda que não tenha sido o foco desse trabalho, além de não haver espaço suficiente para tanto, pudemos perceber a centralidade que a EAD possui na formação de professores de Ciências Sociais/Sociologia nessa região, de modo que esse setor deve ser objeto de análises mais aprofundadas por outros pesquisadores para uma melhor compreensão do cenário da formação docente nessa área do conhecimento, tendo em vista que parecer haver uma tendência para uma manutenção ou mesmo expansão dessa tendência. 
Algumas regiões apresentam ainda desafios próprios, como nos atesta o trabalho de Nunes e Domingues-Lopes (2012) que analisa a realidade do Ensino de Sociologia em Tocantinópolis (UFT), apontando para as dificuldades de inserção profissional dos alunos (incluindo aí no campo do estágio), além de problemas estruturais do próprio curso, que perpassam problemas com o volume das leituras até os limites postos pelo Projeto Pedagógico do Curso.

Ainda que a expansão do número de cursos seja um dado significativo, e que certamente contribui para a possibilidade de consolidar a Sociologia na Educação Básica, já que indica a médio prazo uma maior proporção de professores com formação na área atuando nas escolas, é necessário também que sejam dadas condições de trabalho para estes profissionais, o que inclui um investimento real em formação continuada em sua área de conhecimento, bem como que seja garantido no currículo escolar um espaço para a Sociologia equivalente a outros conteúdos disciplinares.

Em que pese a centralidade crescente do setor privado na formação inicial dos docentes, é importante indicar que as Instituições Públicas continuam representando as principais produtoras de conhecimento no campo das Ciências Sociais na região, o que segue uma tendência nacional. Os cursos de pós-graduação na área de Ciências Sociais atualmente em funcionamento na região são: Antropologia na UFAM, UFPA e UFRR ${ }^{43}$, Sociologia na UFAM, Sociologia e Antropologia na UFPA e Ciência Política na UFPA. Isso significa que essas instituições ainda mantêm sua centralidade na produção do conhecimento, bem como na formação dos quadros profissionais que atuarão em outras instituições na região.

Por fim, chamo a atenção para a necessidade de haver um maior investimento nas pesquisas sobre o Ensino de Sociologia na região, e nesse ponto me parece que a atuação das universidades públicas se mostra fundamental. Recentemente houve a defesa da primeira tese de doutorado sobre Ensino de Sociologia na região, voltando para uma análise acerca da formação de professores de Ciências Sociais na UFPA (FREITAS, 2013), o que ocorre de forma concomitante a uma crescente participação de pesquisadores ligados a instituições da região Norte nos diversos fóruns de discussão acadêmica, este é um passo decisivo para que possamos melhor compreender o fenômeno diante do qual nos deparamos de modo que possamos repensar os atuais modelos formativos ante às reais necessidades postas pelo Ensino de Sociologia na Educação Básica.

43 O Programa de Pós-Graduação em Antropologia da UFRR foi recém aprovado durante a $161^{\text {a }}$ reunião CTC-ES, que ocorreu em dezembro de 2015, de modo que o ingresso de sua primeira turma ocorrerá em 2016. 


\section{REFERÊNCIAS}

BRASIL. Parecer CNE/CES no 492/2001. Diretrizes Curriculares Nacionais dos cursos de Filosofia, História, Geografia, Serviço Social, Comunicação Social, Ciências Sociais, Letras, Biblioteconomia, Arquivologia e Museologia. Diário Oficial da União, Brasília, 9 de julho de 2001.

Parecer CNE/CES no 3/2010. Regulamenta o Art. 52 da Lei no 9.394, de 20 de dezembro de 1996, e dispõe sobre normas e procedimentos para credenciamento e recredenciamento de universidades do Sistema Federal de Ensino. Diário Oficial da União, Brasília, 15 de outubro de 2010. E-MEC. Disponível em < http:// emec. mec.gov.br/>. Último acesso em 2 de nov. 2014.

BRASIL. Guia de livros didáticos: PNLD 2015: sociologia: ensino médio. Brasília: Ministério da Educação, Secretaria de Educação Básica, 2014.

FERNANDES, F. A Sociologia no Brasil. Petrópolis: Vozes, 1980.

FREITAS, L. K. G. de. Currículo e Formação Docente no Curso de Ciências Sociais UFPA: configurações, continuidades e rupturas (1963-2011). 2013. 308. Tese (Doutorado em Educação) - Universidade Federal do Pará, Belém, 2013.

HANDFAS, A. A Formação do Professor de Sociologia. In: ; OLIVEIRA,

Luiz Fernandes. (Org.). A Sociologia vai à escola: história, ensino e docência. Rio de Janeiro: Quartet, 2009.

Formação dos professores de Sociologia: um debate em aberto. In: HANDFAS; MAÇAIRA, J. P. (Org.). Dilemas e Perspectivas da Sociologia na Educação Básica. Rio de Janeiro: e-papers, 2012, p. 11-25.

HANDFAS, A.; MAÇAIRA, J. P. O estado da arte da produção científica sobre o ensino de sociologia na educação básica. BIB, s/v, n. 74, 2014, p. 43-59.

LIMA, J. C.; CORTES, S. M. V. A sociologia no Brasil e a interdisciplinaridade nas ciências sociais. Civitas. v. 13, n. 2, p. 416-435, 2013.

MARTINS, C. B. A Reforma Universitária de 1968 e a abertura para o ensino superior privado do Brasil. Educação \& Sociedade, v. 30, n. 106, p. 15-35, 2009.

MARTINS, C. B.; WEBER, S. Sociologia da Educação: democratização e cidadania. In: MARTINS, Carlos Benedito; MARTINS, Heloisa Helena T. de Souza. Horizontes das Ciências Sociais: Sociologia. São Paulo: ANPOCS, 2010. p. 131-201.

MORAES, A. C. Ensino de Sociologia: periodização e campanha pela obrigatoriedade. Cadernos CEDES, v. 31, p. 359-382, 2011.

Licenciatura em ciências sociais e ensino de sociologia: entre o balanço e o relato. Tempo Social, São Paulo - SP, v. 15, n.1, p. 05-20, 2003. 
NEVES, C. E. B. A estrutura e o funcionamento do ensino superior no Brasil. In:SOARES, M. S. A.. (Org.). A Educação Superior no Brasil. Brasília: Fundação Coordenação de Aperfeiçoamento de Pessoal de Nível Superior, 2002a, p. 43-69.

Estudos Sociológicos sobre Educação no Brasil. In: MICELI, S. (Org.). Oque ler na ciência social brasileira 1970-2002. São Paulo; Brasília: Editora Sumaré;CAPES, 2002b, v. IV, p. 351-437.

NUNES, K. de C. S.; DOMINGUES-LOPES, R. de C. O trabalho docente na Sociologia: histórico e atualidades. In: XV CISO - Encontro Norte e Nordeste de Ciências Sociais, 2012, Teresina. Anais do $\mathbf{1 5}^{\mathbf{a}}$ Encontro de Ciências Sociais do Norte e Nordeste: Desenvolvimento, Meio Ambiente e Paisagem Humana no Norte/Nordeste: Desafios e Perspectivas, 2012.

OLIVEIRA, A. A Formação Inicial de Professores de Sociologia no Nordeste: alguns breves apontamentos. Pesquiseduca, v. 6, n 12, p. 285-299, 2014.

Formação de Professores de Ciências Sociais ante às Políticas Educacionais.

Crítica e Sociedade: revista de cultura política, v. 3, n. 2, p. 132-152, 2013 a.

Revisitando a História do Ensino de Sociologia na Educação Básica. Acta Scientiarum. Education, v. 35, n 2, 2013b.

Um Balanço Sobre o Campo do Ensino de Sociologia no Brasil. Em Tese, v. 12, n. 2, p. 6-16, 2015.

OLIVEIRA, A.; BRUM, C. K. Ciências Sociais à Distância: apontamentos sobre os desafios da formação de professores no Brasil. O Público e o Privado, s/v, n. 24, pp. 26-39, 2014.

OLIVEIRA, A.; SILVA, C. F. Mapeamento da Sociologia da Educação no Brasil: análise de um campo em construção. Atos de Pesquisa em Educação, v. 9, n. 2, p. 289-315, 2014.

PALHANO, E. G. da S. Experiência da Sociologia no Processo Seletivo Seriado (PSS) - antigo vestibular - Universidade Federal do Pará. In: XIII Congresso Brasileiro de Sociologia, 2007, Recife. Anais do XIII Congresso Brasileiro de Sociologia, 2007.

SILVA, G. M. D. da. Sociologia da sociologia da educação: caminhos e desafios de uma policy science no Brasil (1920-79). Bragança Paulista: Universidade São Francisco, 2002.

WEBER, S. A Produção Recente Na Área de Educação. Cadernos de Pesquisa, s/v, n. 81, p. 22-32, 1992.

Formação Docente e Projetos de Sociedade. Revista Brasileira de Política e Administração da Educação, v. 23, n. 2, p. 181-198, 2007. 